\title{
Daniel M. Sáez Rivera/ Álvaro S. Octavio de Toledo y Huerta: Textos españoles de la primera mitad del siglo XVIII para la historia gramatical y discursiva. Ma- drid: Síntesis, 2020, $45^{8}$ pp. ISBN: 9788413570143.
}

El siglo XVIII, considerado la frontera entre el español clásico y el moderno, ha sido tradicionalmente poco (y a veces mal) estudiado. La antología de textos que reseñamos, al cuidado de Daniel Sáez y Álvaro Octavio de Toledo, viene a cubrir parcialmente algunas de esas lagunas derivadas de la carencia y falta de profundización de los estudios, así como de la infrarrepresentación de textos de esta época en los corpus y la escasez de textos editados (exceptuando aquellos que están bendecidos por el canon literario). Siguiendo la consolidada tradición de antologías en el ámbito de la filología española, inaugurada por la Crestomatía de Pidal, los autores se ocupan de la primera mitad del siglo XVIII, que se considera una de las etapas del primer español moderno o español moderno temprano, término acuñado por Octavio de Toledo (2007) y desarrollado en trabajos posteriores $(2008 ; 2016 ; 2017$, junto con la profesora López Serena). A través de la edición paleográfica de 6 o textos, podemos estudiar lingüística y extralingüísticamente (gracias a las obras historiográficas antologadas) un siglo lleno de polémicas lingüísticas, literarias y científicas que llegan a ser, incluso, personales.

Ya en el prólogo (pp. 13-14) el profesor Girón Alconchel, también especialista en el análisis de textos del español moderno, destaca no solo la idoneidad de examinar textos del XVIII, sino también de hacerlo teniendo en cuenta tipologías textuales diferentes que es, precisamente, uno de los objetivos principales de esta antología. Al prólogo le sigue una introducción a cargo de los autores en la que se explican los pormenores de la edición: desde los criterios de selección de los textos, donde se pone de relieve la importancia y necesidad de profundizar en el estudio lingüístico de este siglo, además de presentar la diversidad de tradiciones discursivas del volumen (pp. 15-28), pasando por los criterios de edición y presentación de dichos textos (pp. 28-31), en los que se incluye una tabla que recoge las abreviaturas (en su mayoría fórmulas de tratamiento) más repetidas.

Así, en este florilegio se reúnen textos que circularon en la primera mitad del XVIII tanto impresos como manuscritos, que dan a conocer una gran variedad de tradiciones discursivas. Lejos de subrayar, una vez más, la escasa influencia de las medidas académicas en estos primeros compases del XVIII, Octavio de Toledo y 
Sáez pretenden recalcar el peso que tuvieron los impresos como promotores de la norma en este primer español moderno (p. 16). Precisamente por la creación de la Real Academia Española en 1713 y los diccionarios y gramáticas que nacieron en su seno, la lengua del XVIII se ha considerado tradicionalmente como una etapa más estable, incluso de "estasis lingüística" (p. 18), siendo las diferencias con la lengua actual "cuantitativa y cualitativamente menores y más sutiles" (Octavio de Toledo/ Pons, 2016: 16) y, por ello, menos digna de estudio que otras con cambios que podríamos denominar más revolucionarios. A este argumento se suma, además, la idea de que en el XVIII se produjo un absoluto "hundimiento cultural" (p. 19); la ausencia de un canon literario establecido en el XVIII (pp. 18-19) y la escasez de textos para el estudio lingüístico (p. 20). De este modo, se ha gestado el caldo de cultivo ideal para que pocos lingüistas se hayan interesado por el Setecientos. No obstante, los autores señalan cómo en los últimos años algunos estudiosos se han dedicado a recopilar y estudiar la transición del siglo XVII al XVIII (p. 21-22). Entre ellos, se encuentran los propios Sáez y Octavio de Toledo (cf. Sáez, 2006 y Guzmán/ Sáez, 2016), así como el profesor Girón Alconchel (2002, 2012) o García Godoy (2012). La mayoría de ellos se dedican a la morfosintaxis, dado que los cambios fonéticos fueron realmente escasos en este período (p. 21).

Si bien es cierto que los estudios han proliferado, Sáez y Octavio de Toledo afirman que sigue habiendo un problema latente que impide avanzar a los lingüistas: la escasez de textos accesibles a la comunidad investigadora que sean representativos de cada tradición discursiva (p. 20). Asimismo, se hace necesario estudiar en profundidad la variación concepcional y clasificar los fenómenos producidos durante estos 100 años en "procesos de largo recorrido" que aún en el XVIII no están asentados; fenómenos prestigiosos presentes en textos más cercanos a la distancia comunicativa; "zonas de la gramática" con una configuración que dista de la actual y, por último, cambios producidos únicamente durante el transcurso del XVIII (p. 23). Este índice, aunque aparentemente sencillo, puede resultar provechoso para aquellos que trabajan con textos de esta etapa del primer español moderno (cf. Octavio de Toledo, 2016 para un estudio en profundidad de estos procesos).

Por todo lo anterior, se pone de manifiesto la idoneidad de escoger textos de variada tipología donde se vean reflejados diversos ejemplos de los fenómenos expuestos (p. 23). Por otro lado, que se dedique unos párrafos a definir términos cruciales para la organización y clasificación del corpus escogido no está de más. Bajo la denominación de tradición discursiva (Kabatek, 2005) o universos del discurso (Coseriu, 2006) se pretenden establecer los elementos que nos permiten agrupar fenómenos que se repiten en un mismo tipo textual y, además, entablar relaciones entre tipos textuales diferentes (pp. 25-27).

En lo que concierne a los criterios de edición y presentación de los textos (pp. 283o), los autores han optado por una transcripción semipaleográfica en la que se respetan grafías y signos de puntuación originales, pero no se indican los cambios de línea (sí de folio) y, a veces, se interviene en el texto en aras de una mayor claridad, 
siempre indicándolo entre corchetes. Lejos de que esta transcripción fiel sea un impedimento para aquellos que no son lingüistas, el sistema gráfico del Setecientos es muy similar al contemporáneo y, por tanto, la comprensión del texto no es una tarea tan ardua; por otro lado, este tipo de edición ofrece al historiador de la lengua un material interesante para el análisis gráfico (pp. 24-25). Los textos escogidos son fragmentos representativos de la obra en cuestión y van precedidos de una cabecera donde se indican el título, el autor (en ocasiones con datos relevantes de la vida de este), la fecha y el lugar de composición o impresión y, por último, una descripción física pormenorizada de la obra (p. 30).

El volumen se divide en dos partes. La primera, de la que se ocupa el profesor Sáez Rivera, incluye diversos textos del primer cuarto de siglo como novelas pastoriles ( $(1-\S 2)$, obras historiográficas $(\S 3-\S 6)$ a las que nos referiremos pormenorizadamente, obras teológicas $(\S 7-\S 9$; 11), diálogos de diversa temática $(§ 12$ y $§ 13$; $\S 18$ ), obras de interés metalingüístico (como la de Alvarado, que podríamos considerar precursora de los métodos de ELE, § 13 y la primera acta de la RAE, § 15), obras científicas, en su mayoría en forma de tratados ( $§ 19-\S 23)$ y una muestra de uno de los tratados de misivas más importantes en la España del XVIII ( $§ 25$; sobre la figura de Sobrino, cf. Sáez, 2002). La segunda, de la que se encarga Octavio de Toledo, se compone de 35 obras del segundo cuarto, entre las que podemos leer textos de naturaleza tan variada como obras literarias ( $\$ 26-\S 30)$, algunas de las cuales entroncan con la vertiente costumbrista que se desarrollará por extenso en el XIX ( $(31-\S 33)$ e, incluso, un cuento, forma textual no muy común por entonces ( $\$ 34)$; no falta la historiografía $(\S 35$ y $§ 36$ ) ni las obras de carácter religioso ( $§ 37-\S 39)$, además de una célebre obra de Gregorio Mayans (Orígenes de la lengua española, § 40); también se presenta una selección de obras que tradicionalmente han sido estudiadas desde un punto de vista literario, pero rara vez lingüístico (como la Poética de Luzán, § 41, o el Teatro crítico de Feijoo, § 43). Esta segunda parte también incluye obras filosóficas escritas por partidarios de la corriente de pensamiento renovadora ( $\$ 44$ y $§ 45$ ), obras de tema jurídico escritas por doctos abogados ( 553 y $§ 54$ ) y cartas personales de nobles ilustres $(§ 55$ y $§ 56$ ). El siglo XVIII también nos dejó curiosos textos como almanaques, pronósticos y lunarios, todos ellos con el propósito de predecir algún aspecto del futuro (una muestra en $§ 57$ ). La obra se cierra, muy acertadamente, con el Epítome en la muerte de Felipe $V(\S 60)$, fallecido el 9 de julio de 1746 , fecha que queda marcada en la historia de España por el fin de la primera mitad de siglo y la muerte del primer Borbón.

Tanto las ciencias experimentales como la historiografía sufrieron un gran impulso en esa primera mitad de siglo por la llegada de la Ilustración que, aunque de manera tímida, iba introduciendo renovaciones en España. Prueba de ello es que los historiadores se comienzan a preocupar por la historia como objeto de estudio científico, y se valen de fuentes de las que dejan constancia, como Feliú de la Peña en sus Anales de Cataluña (§ 3). Algunas de ellas dieron lugar, también, a ciertas polémicas lingüísticas, como la que suscitó Álvarez de Toledo en la Historia de 
la Iglesia y del mundo (§ 4). Una gran ventaja de esta antología es que los textos no se presentan inconexos, sino que guardan cierta relación entre sí. Siguiendo con el caso de Álvarez de Toledo, uno de sus principales detractores fue Luis Salazar y Castro (en § 16) quien dice que "no avrà Castellano que lo entienda [el libro de Álvarez de Toledo] sin ayuda de otro Idioma" (p. 189). Vicente Bacallar salió en defensa de la obra trayendo a colación figuras notables que usan los términos que Salazar censura y, además, se burla de la ortografía de este. Así, podemos leer en $\S 17$ que "Avitar es una voz de marineria: tu como fuiste mal marinero [...] no entiendes los terminos Nauticos" (p. 192).

La revolución ilustrada también llegó, como hemos anunciado, al terreno de las ciencias españolas. Alejandro de Avendaño (o fray Juan de Nájera) escribe el Diálogo atomista-aristotélico (§18), donde deja constancia de que "las opiniones de los Antiguos Philosophos se renovaron en el siglo passado" (p. 196). A estos novatores se refería López de Araujo como la "Secta de los Scepticos", porque se oponían a "todos los principios de nuestra Santa Fè" (§ 19, pp. 208-209). A pesar de que no era el propósito de los autores (o, al menos, eso revela el título), los tratados científicos son una ingente fuente de nuevo léxico que se incorpora al idioma durante estos años y, por ello, un interesante objeto de estudio para los lingüistas.

Las obras literarias del XVIII son de las pocas que están representadas textualmente en los corpus de manera representativa (Pons, 2006: 70). Los textos literarios adquieren en estos años "una textura peculiar; que exhibe tendencias propias, progresos y regresiones” (Octavio de Toledo, 2016: 195). Estas obras precisan, para su análisis, de una buena edición paleográfica que permita estudiar la lengua de la época en profundidad y, concretamente, prestar atención a las variantes de lengua que son a menudo ignoradas en las ediciones literarias (cf. Fernández Ordóñez, 2019). Por ello, en esta compilación se incluyen fragmentos de Visiones y Visitas (§ 26) y Vida, ascendencia, nacimiento, crianza y aventuras (§ 27) de Torres de Villaroel (que sí ha sido un autor estudiado lingüísticamente; Octavio de Toledo, 2016: 194). Asimismo, los diversos ejemplos cercanos a la literatura costumbrista, que se han tomado en diversas ocasiones para intentar caracterizar el habla madrileña, son también susceptibles de análisis, como la obra de Antonio Muñoz (§ 33), dirigida a un público popular y cuyos diálogos imitan la sintaxis propia de la inmediatez comunicativa. La única obra de la antología que no se inserta en la primera mitad de siglo es el Fray Gerundio de Campazas (§ 30), obra que merece, sin duda, ser la excepción por su calidad literaria y su complejísima tradición textual (cf. Jurado, 1982) que la hacen (sobre todo este último factor) un objeto de análisis especialmente atrayente para el crítico textual y el historiador de la lengua. Uno de los capítulos escogidos (cuarto, libro I) versa sobre la presentación del héroe, aunque algo peculiar, porque su historia no es un poema épico, sino "prosa lisa, y llana, y harto ratera" (p. 271).

En definitiva, esta antología permite estudiar como documentos textos que tradicionalmente no se han considerado monumentos (Pons, 2006: 105), ofreciendo 
una exhaustiva nómina de 6o textos pertenecientes a diferentes TD y con rasgos significativos para esta época que se encuadran en una de las categorías propuestas por Octavio de Toledo (2016). Este compendio de textos despertará el interés de no pocos investigadores (como esta que escribe) para continuar profundizando en el estudio de los cambios y los no cambios (cf. Girón Alconchel, 2012) que tuvieron lugar en el Setecientos. El trabajo de Sáez y Octavio de Toledo es una obra muy útil para iluminar algunas de cuestiones lingüísticas que a día de hoy están, todavía, irresolutas y, por ello, esperamos que su trabajo tenga continuación en investigaciones futuras.

\section{REFERENCIAS BIBLIOGRÁFICAS}

Octavio de Toledo y Huerta, A. S. (2016). Antonio Muñoz y la sintaxis de la lengua literaria durante el primer español moderno (ca. 1875-1825). En M. Guzmán y D.M. Sáez (Eds.), Márgenes y centros en el español del siglo XVIII (pp. 192-29o). Tirant lo Blanch.

Octavio de Toledo y Huerta, A. S. y Pons Rodríguez, L. (2016). Queja política y escritura epistolar durante la Guerra de la Independencia: documentación de la Suprema Junta Central en el Archivo Histórico Nacional. Universidad de Alcalá de Henares.

Pons Rodríguez, L. (2006). Canon, edición de textos e historia de la lengua cuatrocentista. En L. Pons (Ed.), Historia de la Lengua y Crítica Textual (pp. 69-125). Iberoamericana/ Vervuert.

Sáez Rivera, D.M. y Guzmán Riverón, M. (Coords.) (2016). Márgenes y centros en el español del siglo XVIII. Tirant lo Blanch.

Irene Roldán González

Universidad Autónoma de Madrid

irene.roldan@uam.es

ORCID: oooo-ooo1-7774-2596 